\title{
ON THE POSSIBILITIES OF APPLICATION OF EXCHANGE DISCHARGE MODEL IN ESTIMATION OF A RATING CURVE AT A RIVER GAUGING STATION
}

\author{
DEJANA ĐORĐEVIĆ(1), MARIJA IVKOVIĆ(2)\&IVAN STOJNIĆ(3) \\ ${ }^{(1)}$ University of Belgrade, Faculty of Civil Engineering, Belgrade, Serbia \\ dejana@grf.bg.ac.rs \\ (2) Republic Hydro-meteorological Service of Serbia, Belgrade, Serbia \\ marija.ivkovic@hidmet.gov.rs

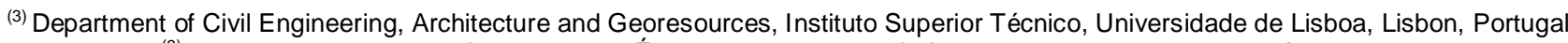 \\ (3) Laboratory of Hydraulic Constructions, École Polytechnique Fédérale de Lausanne, Lausanne, Switzerland \\ ivanstojnic@tecnico.ulisboa.pt
}

\begin{abstract}
The exchange discharge model (EDM) is the model that was developed for the estimation of a stagedischarge curve and flood routing in compound channels. It was thoroughly tested against experimental data in different compound channel layouts. However, there is a little evidence on its application in rivers. This paper studies EDM performance in estimating stage-discharge curve at two gauging stations on the same river with different hydraulic conditions and compares its results with the traditional, divided channel method (DCM). The contribution of momentum fluxes due to turbulence diffusion and mass exchange to the total energy loss are analysed. It is found that EDM parameter values $\left(\psi^{t}\right.$ and $\left.\psi^{g}\right)$ depend on the hydraulic conditions at a gauging station. In the case of M1-type water surface profile, the $\psi^{t}$-value increases and the effect of mass transfer is negligible. In the case of M2-type profile, the $\psi^{t}$-value decreases and the momentum flux due to mass transfer becomes dominant. Nonetheless, the lower $\psi^{t}$-value does not result in smaller additional loss due to turbulence diffusion, since the velocity difference between the main channel and the floodplain increases. Although the EDM and DCM provide approximately the same total discharge, EDM gives more realistic discharge distribution (main channel discharge is reduced and that on the floodplain is increased by $30-40 \%$ due to mass transfer caused by non-prismaticity of the channel).
\end{abstract}

Keywords: Non-prismatic compound channel, momentum flux due to turbulence and mass exchange, energy loss

\section{INTRODUCTION}

Major damages and large number of casualties due to the severe flood events have become more frequent in recent decades. At the same time, the movements for the protection of wildlife and, among other things, wetland habitats have become influential in decision making in the water resources sector including flood management. This gave rise to the abandonment of the formerly widespread practice of straightening river channels and clearing floodplain vegetation to achieve hydraulic capacity during high, overbank flows (Shiono and Knight, 1987). Consequently, a need for better understanding of flood channel hydraulics arose. Following this deficiency in understanding the overbank flows, the IAHR Working group on compound channels was established by UK and Japanese members in the early 1990ies (Ikeda and McEwan, 2009). Continuous efforts have been making to improve estimation of stage-discharge curves and computation of water surface profiles in a compound channel since then. Reliable calculation of the stage-discharge curve for overbank stages is of paramount importance for: 1) the estimation of the peak high-flow discharge based on either recorded flood marks or the maximum recorded stage at the gauging station, 2) the reconstruction of the flood or high-flow hydrographs and 3) the water surface profile computations. A number of laboratory experiments (Ikeda and McEwan, 2009, Proust et al. 2006, 2009, 2013, Das and Khatua, 2018) have shown that the widely used traditional method in the hydraulic engineering practice - the divided channel method (DCM) overestimates both the total and the main channel discharges and underestimates those on the floodplains for high floodplain submergence ratios $\left(H_{\star}=h_{f p} / H>0.3\right.$, where $h_{f p}$ is the flow depth on the floodplain and $H$ is the flow depth in the main channel, see Fig.1; Bousmar and Zech, 1999; Đorđević et al., 2015). The overestimation of the main channel discharge can be as high as $60 \%$ for the highest $H_{*}$-values. To alleviate the latter discrepancies and improve stage-discharge calculation, two 1D models that account for energy dissipation due to exchange of momentum between the main channel and floodplains were proposed thus far - the Exchange Discharge Model (EDM) by Bousmar and Zech (1999), and the Independent Subsections Model (ISM), by Proust et al. (2009). Both models were successfully tested against the experimental data for uniform flows (Bousmar and Zech, 1999; Proust et al. 2009; Đorđević et al., 2015; 
Stojnić et al. 2015) and non-uniform flows in two-stage laboratory canals with smooth and rough floodplains (Bousmar et al., 2004, 2006; Proust et al. 2009; Đorđević et al., 2017).

This paper aims at assessing the performance of the EDM in estimating the stage-discharge curve in rivers with non-prismatic compound channels of an arbitrary cross-sections' shape and variable floodplain widths. To the authors' knowledge, apart from its validation in the River Sambre in Belgium (Bousmar and Zech, 1999) and River Kolubara in Serbia (Đorđević et al., 2018), there is little evidence on the EDM application in rivers. Thus, two gauging stations (GSs) on the Tamiš River in Serbia with different floodplain layouts and different hydraulic conditions (HCs) are chosen to assess the contribution of different terms that describe momentum transfer between the main channel and floodplains to the total energy loss. These are the turbulent momentum flux and geometrical mass exchange caused by variable floodplain width.

\section{GOVERNING EQUATIONS}

Compound channel with a cross-section of an arbitrary shape can be decomposed into three hydraulically homogeneous subsections (Fig. 1) where velocity field can be assumed uniform (Bousmar and Zech, 1999). One-dimensional unsteady flow in such a channel is described by three sets of the mass and momentum conservation equations, each of which is written for the corresponding subsection. The influence of the adjacent subsection is taken into account by introducing additional terms into the two equations, i.e. the lateral flow per unit length $\left(q_{l}\right)$ in mass conservation equations and the momentum transfer through the main channel-floodplain interface $\left(\rho q_{l} u\right)$ in the momentum equations. Lateral flow per unit length can be further decomposed into the inflow $\left(q_{i n}\right)$ and the outflow $\left(q_{\text {out }}\right)$ components, while the momentum flux into the subsection is decomposed into the one carried by the velocity from adjacent subsection $\left(\rho q_{i n} u_{\text {lat }}\right)$ and the other, carried by the mean velocity of the considered subsection $\left(\rho q_{o u t} U\right)$. The governing equations thus read:

Mass conservation equations:

$$
\frac{\partial A_{i}}{\partial t}+\frac{\partial Q_{i}}{\partial x}=q_{i, l a t}=q_{i, \text { in }}-q_{i, \text { out }}, \quad i=1,2,3
$$

Momentum conservation equations

$$
\frac{\partial}{\partial t}(\rho A U)_{i}+\frac{\partial}{\partial x}\left(\rho A U^{2}\right)_{i}+\rho g A_{i} \frac{\partial Z}{\partial x}+\rho g A_{i} S_{f, i}-\rho q_{i, \text { in }} u_{i, \text { lat }}+\rho q_{i, \text { out }} U_{i}=0, i=1,2,3
$$

where the time $t$ and the space coordinate $x$ are independent variables, and subsection area $A_{i}$ and subsection discharge $Q_{i}$ are dependent variables. Sub-sectional mean velocity is denoted by $U_{i}\left(=Q_{i} / A_{i}\right)$, while $u_{i}$ lat is the stream-wise velocity in the adjacent subsection by which the momentum is transferred to the considered one. Water level in the compound channel cross-section $Z$ is assumed horizontal. Water density is denoted by $\rho$, the gravity acceleration by $g$ and the friction slope by $S_{f, i}$. In the development of the exchange discharge model for estimation of the rating (stage-discharge) curve in a compound channel, Bousmar and Zech (1999) assume that the flow is steady and non-uniform. Thus, after neglecting local accelerations and some algebraic transformations, the momentum equations [2] are simplified to the energy conservation equation:

$$
S_{e} \equiv-\frac{\partial}{\partial x}\left(Z+\frac{U^{2}}{2 g}\right)=S_{f, i}+\underbrace{\frac{q_{i, i n}\left(U_{i}-u_{i, l a t}\right)}{g A_{i}}}_{S_{a, i}}, i=1,2,3
$$

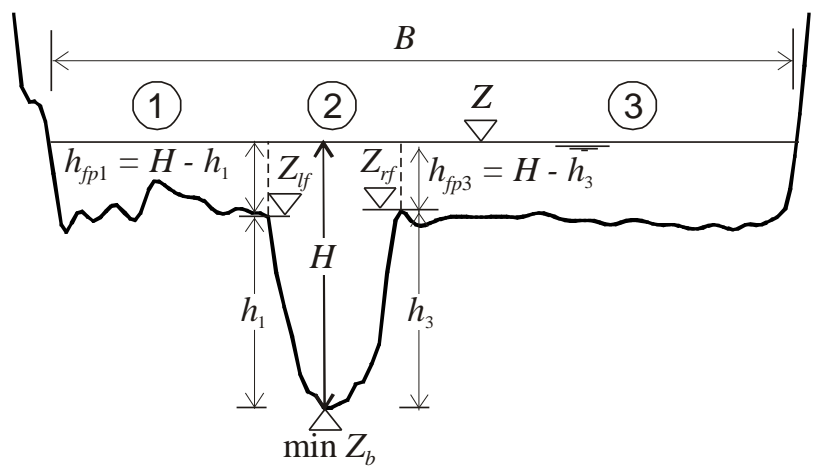


Figure 1. Cross-section of the compound, river channel

According to Eq.[3] the energy grade line slope (total head slope) $S_{e}$ comprises the portion that results from the friction on the bed $\left(S_{f}\right)$ and additional losses due to exchange discharges $\left(S_{a}\right)$. The ratio of the two for each subsection is denoted by $\chi_{i}=S_{a, i} / S_{f, i}$. Thus, the Equation [3] can be written in a compact form: $S_{e}=S_{f, i}\left(1+\chi_{i}\right)$, $i=1,2,3$.

A part of the inflow discharge originates from the turbulence diffusion $\left(q_{i n}^{t}\right)$ and the other from the modification of the flow distribution in the cross-section due to change in the cross-sectional conveyance in non-prismatic channels $\left(q_{i n}^{g}\right)$. The later one is so called "geometrical transfer discharge" and it is explained in Bousmar and Zech (1999) and Bousmar et al. (2004). The two authors model lateral discharge due to momentum flux caused by turbulence diffusion using the model analogy to the mixing length model:

$$
q_{m f p}^{t}=q_{f p m}^{t}=\left|\overline{v^{\prime}}\right|\left(H-h_{f p}\right)=\psi^{t}\left|U_{m}-U_{f p}\right|\left(H-h_{f p}\right)
$$

where $\left|\overline{v^{\prime}}\right|$ is the depth-averaged fluctuation of the lateral velocity component, and $H-h_{f p}$ is the flow depth at the main channel-floodplain interface (Fig. 1). Bousmar and Zech assume that $\left|\overline{v^{\prime}}\right|$ is proportional to the difference between mean velocities in the main channel and the floodplain $\left|U_{m}-U_{f p}\right|$. The proportionality coefficient is $\psi^{t}$. This coefficient is a model parameter and it requires calibration.

The geometrical transfer discharge is assumed proportional to the gradient in floodplain conveyance along the non-prismatic channel $\mathrm{d} K_{f p} / \mathrm{d} x$. Its sign depends on the floodplain layout. When the floodplain narrows, the flow enters the main channel from the floodplain $\left(q_{f p m}\right)$, whereas in the opposite case the mass is transferred from the main channel to the floodplain $\left(q_{m f p}\right)$. The unit discharges are defined as follows:

$$
q_{f p m}^{g}=\psi^{g} \kappa_{f p m} \frac{\mathrm{d} K_{f p}}{\mathrm{~d} x} S_{f, f p}^{1 / 2} \text { and } q_{m f}^{g}=\psi^{g} \kappa_{m f p} \frac{\mathrm{d} K_{f p}}{\mathrm{~d} x} S_{f, f p}^{1 / 2}
$$

Here, again, a proportionality coefficient $\psi^{g}$ is introduced. The parameter $\kappa$ takes into account the mass transfer direction:

$$
\kappa_{f p m}=\left\{\begin{array}{cc}
0, & \frac{\mathrm{d} K_{f p}}{\mathrm{~d} x}>0 \\
-1, & \frac{\mathrm{d} K_{f p}}{\mathrm{~d} x}<0
\end{array} \wedge \kappa_{m f p}=\left\{\begin{array}{cc}
1, & \frac{\mathrm{d} K_{f p}}{\mathrm{~d} x}>0 \\
0, & \frac{\mathrm{d} K_{f p}}{\mathrm{~d} x}<0
\end{array}\right.\right.
$$

When the flow direction coincides with the unit vector of the outter normal, $\kappa=1$, i.e. the water flows out of the main channel to the floodplain. On the other hand, when the flow is in the opposite direction of the unit vector of the outter normal, $\kappa=-1$, and the water returns back from the floodplain to the main channel. The $\kappa$-value of 0 indicates that the flow enters the considered subsection from the adjacent one. The solving procedure for three $\chi_{i}$ values is explained in Bousmar and Zech (1999). Here, only the expression for the total crosssectional discharge is given:

$$
Q=\sum_{i=1}^{3} \frac{K_{i}}{\left(1+\chi_{i}\right)^{1 / 2}} S_{e}^{1 / 2}
$$

To facilitate assessment of the contribution of the two components of the momentum transfer to the total head loss, additional loss $S_{a}$ is divided into two components according to Eqs. [3-6] after the solution is reached. The one originating from the turbulence diffusion is denoted by $S_{a}^{t}$, and that originating from the mass transfer due to unprismatical compound channel (variable floodplain width) is denoted by $S_{a}^{m}$. 


\section{SITE DESCRIPTION}

Two gauging stations on the Tamiš River in Serbia are chosen to assess the EDM performance in estimation of stage-discharge curve in natural river channel. The source of the Tamiš River is in Carpatian Mountains in Romania. Tamiš River is a transboundary river between Serbia and Romania and it is left tributary of the Danube River. In the lower course it runs through flat arable lands of the Banat region in Serbia where a complex system of the irrigation and drainage canals is made to facilitate agriculture. One of the major stems crosses the river some $35 \mathrm{~km}$ downstream of the border where the sluice gate is installed to control the drainage from the upstream side. The valley of the Tamiš River is constrained by embankments to protect the area from flooding by overbank flows.

The two gauging stations are located on the river reach just downstream of the country border where heavy flooding occurred due to a failure of the embankment in 2005 . The two GSs are approximately $15 \mathrm{~km}$ apart. The variable position of the channel between the embankments on one hand and the irregular shape of the embankment line on the other (Fig.2) offer an opportunity to study both the contribution of the turbulence diffusion to the total head loss and that of the unprismatical shape of the compound channel to the total head loss. The data necessary for estimation of the conveyance gradient are summarised in the table supplied with the Figure 2. As it can be noticed, the change of the floodplain width takes place on different floodplain lengths. The estimated piezometric slope on the study reach is 0.00014 .

\section{CALIBRATION OF MODEL PARAMETERS}

The calibration advanced in several steps. The RMSE was used as a measure of the goodness of fit between the calculated and the measured data:

$$
R M S E=\sqrt{\frac{1}{N} \sum_{1}^{N}\left(Q_{m}-Q_{c}\right)^{2}}
$$

where $Q_{m}$ is the discharge measured at the gauging station, $Q_{c}$ is the discharge calculated by the model, and $N$ is the number of measurements of high flows.
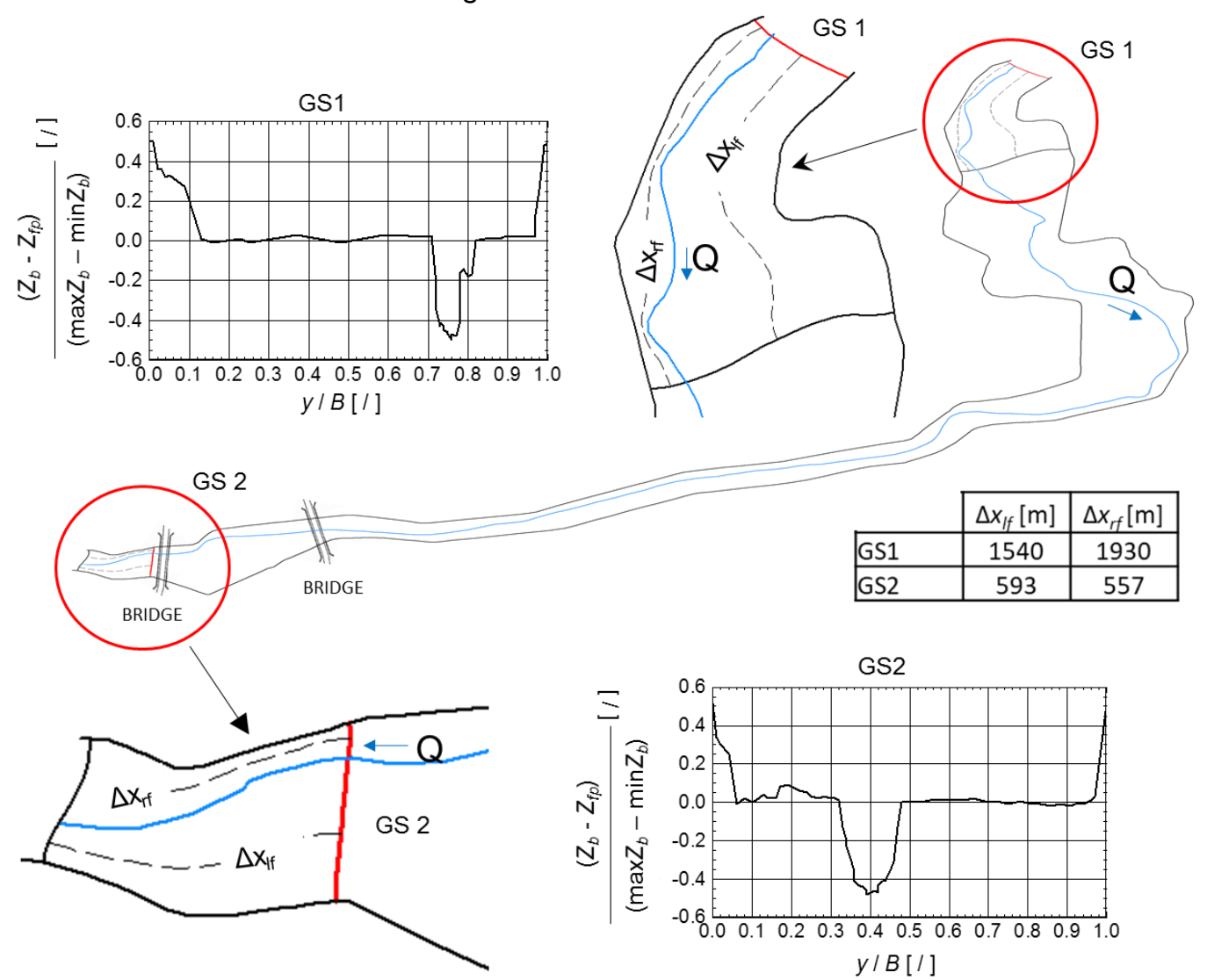

Figure 2. River Tamiš, Serbia: Plan view of the compound river channel with embankment lines, the location of the two gauging stations (GS1 and GS2) and their cross-sections 
The Manning's coefficient for the main channel $\left(n_{m c}\right)$ was calibrated first against the data from the GS1 collected before the installment of the sluice gate. It was shown that the best fit for the discharges less than the bankfull discharge could be achieved with $n_{m c}=0.020 \mathrm{~m}^{-1 / 3} \mathrm{~s}$. The $R M S E$ for this $n_{m c}$-value was $4.60 \mathrm{~m}^{3} / \mathrm{s}$, which is less than $5 \%$ of the bankfull discharge $\left(Q_{b f}\right)$. Prior to the estimation of the EDM parameters, the value of the Manning's coefficient for the floodplains $\left(n_{t p}\right)$ was assessed using the DCM. In this manner, the overall head loss in the compound channel was assessed without clear distinction of the contributions of different sources of head losses to the total head loss. The Manning's coefficient value for the floodplain $\left(n_{f_{p}}\right)$ was adjusted to achieve the best fit with the measurements for the overbank flow for the period after the installment of the sluice gate. The value of $0.055 \mathrm{~m}^{-1 / 3} \mathrm{~s}$ provided $R M S E=43.36 \mathrm{~m}^{3} / \mathrm{s}$ which is approximately $13 \%$ of the average measured high flow discharge $\left(\overline{Q_{m}}\right)$. In the following step a part of the losses, that were encountered in the previous step solely by the Manning's coefficient, was assigned to the head losses induced by the turbulence exchange discharge and the geometrical transfer discharge. The optimal EDM parameter values were $\psi^{t}=0.10$ and $\psi^{g}=0.5$. This resulted in the reduction in the $n_{t p}$-value by approximately $30 \%$ i.e. to $n_{f p}=0.039 \mathrm{~m}^{-1 / 3} \mathrm{~s}$. The agreement with the measurements slightly improved (Fig.3a) giving the $R M S E$-value of $41.67 \%$.

The $n_{m c}$-value for the GS2 was succeeded from the GS1 $\left(n_{m c}=0.020 \mathrm{~m}^{-1 / 3} \mathrm{~s}\right)$. The DCM gave $n_{i p}$-value of $0.040 \mathrm{~m}^{-1 / 3} \mathrm{~s}$ for this GS and $R M S E=9.19 \mathrm{~m}^{3} / \mathrm{s}$ (or $3.13 \%$ of the $\overline{Q_{m}}$; Fig 3b). The following values of $n_{f p}, \psi^{t}$ and $\psi^{g}$ at the GS2 were obtained: $n_{\mathfrak{f}}=0.039 \mathrm{~m}^{-1 / 3} \mathrm{~s}, \psi^{t}=0.10$ and $\psi^{g}=0.5$ giving the $R M S E$-value of $5.16 \mathrm{~m}^{3} / \mathrm{s}$ (or $2 \%$ of $\overline{Q_{m}}$; Fig.3b).
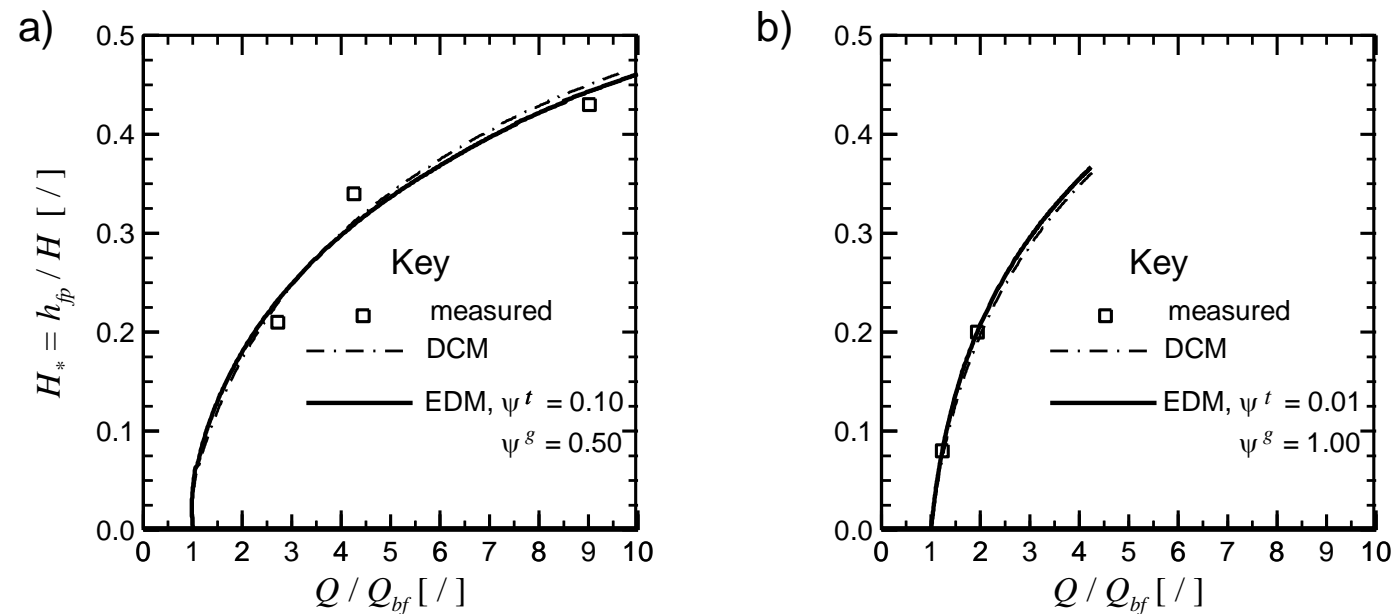

Figure 3. Results of calibration of the EDM parameters for the stage-discharge curves at a) GS1 and b) GS2

\section{MODEL VALIDATION}

\subsection{Rating curves}

The calibrated EDM parameters for the two GS were used to define rating curves for years other than those used for their calibration. The curves are presented in Figure 4. The $R M S E$ at the GS1 is $27.67 \mathrm{~m}^{-1 / 3} \mathrm{~s}$, or $7.8 \%$ of $\overline{Q_{m}}$ (Fig.4a), while for the GS2 it amounts to $60.93 \mathrm{~m}^{3} / \mathrm{s}$, or $14.54 \%$ of $\overline{Q_{m}}$ (Fig.4b). As it can be noticed, the calibrated EDM parameter values provide acceptable agreement of the rating curve at the GS1 with measurements. The RMSE for the GS1 is reduced by $34 \%$ when compared to the calibration step. At the GS2 the situation is quite different - the RMSE is considerably increased, but it is still within acceptable range of differences between the calculated and measured values.

The official rating curve of the Republic Hydrometeorological Service of Serbia is also shown on Figure 4a. The two curves overlap for $H_{*} \in[0.28,0.35]$. Both for the smaller $\left(H_{*}<0.28\right)$ and the larger flow depths on the floodplains $\left(H_{\star}>0.35\right)$ the official rating curve overestimates the discharge. For $H_{\star}<0.28$ the discharge is overestimated by $0.60 Q_{b f}$, whereas for $H_{\star}>0.35$ the over prediction goes beyond $Q_{b f}$. Additionally, the $R M S E=33.8 \mathrm{~m}^{-1 / 3} \mathrm{~s}$, which is greater than that obtained using the EDM.

It is also interesting to observe that the DCM overestimates the discharge regardless of the $H_{\star}$-value at the GS2 (Fig. 3b and 4c), which is under the influence of the operation of the downstream sluice gate. At this GS the water surface profile at high $H_{*}$-values is of M2-type and the results are consistent with those observed by 
comparison with the laboratory data (Bousmar and Zech, 1999, Đorđević et al., 2015). The discharge is by $4 \%$ greater than that obtained by the EDM for the validation step, and $3 \%$ greater in the calibration step in which the EDM prediction almost coincides with the measurements. The difference between the two methods at the GS2 is within the measurement error.

The water surface profile at the GS1 is of M1-type due to a strong backwater effect of the two downstream bridges. In this case, the two rating curves cross each other at approximately $0.28 H_{*}$. Again, both the under prediction and the over prediction by the DCM when compared to EDM are around $5 \%$, which is within the measurement error. However, the discharge distribution between the subsections for DCM and EDM is quite different as already noticed in laboratory experiments (Bousmar and Zech, 1999, Đorđević et al., 2015)(Fig.4b). Although there are no measurement data for evaluation of the models' performance in the field, a comparison between the two models is made. As it can be noticed, the DCM, which does not account for the momentum exchange between the main channel and the floodplains, gives greater discharge in the main channel than the EDM and, consequently, smaller discharges on the floodplains. Discharges in the main channel are greater by $45 \%$ on the average. Those on the left floodplain are smaller by approximately $30 \%$ and on the right floodplain by approximately $40 \%$. These observations should be confirmed by comparison with the measurements.

\subsection{Components of the total head loss}

Contribution of different sources of energy dissipation to the total head loss (i.e. the friction $\left(S_{f}\right)$, the turbulent momentum flux $\left(S_{a}^{t}\right)$ and the momentum flux due to mass exchange $\left.\left(S_{a}^{m}\right)\right)$ for the two gauging stations are presented in Figure 5. It is readily noticeable that the difference in the HCs at the two gauging stations affects the distribution between the three components of the head loss. It is suspected that the loss due to the mass exchange at the GS2 (Fig. $5 b$ ) is negligible as long as there is a significant backwater influence caused by the operation of the downstream sluice gate. The influence of the geometrical exchange becomes relevant from $H_{\star}>0.20$, when the M2-type water surface profile, with larger piezometric slope is established. Under these conditions the geometrical exchange consistently increases with the increasing $H_{*}$ (Fig.5b). The two bridges downstream from the GS1 (Fig.2) cause backwater effect at high flows (M1-type water surface profile). This might be the reason why there is no contribution of mass exchange to $S_{e}$ at the GS1 (Fig. 5a). The addition of the turbulence exchange $\left(S_{a}^{t}\right)$ is almost the same at both GS for all $H_{*}$-values.

It is approximately $3.0 \times 10^{-5}$. The greater piezometric slope at the GS2 produces greater velocity difference between the main channel and the floodplains, which might explain lower $\psi^{t}$-values at the GS2 than those at the GS1 where the velocity difference is much lower, due to the backwater effect of the two downstream bridges. The friction loss is almost constant at the GS2 regardless of the $H_{*}$-values $\left(S_{f} \approx 22 \times 10^{-5}\right)$, whereas at the GS1 it gradually reduces from $6.8 \times 10^{-5}$ to $4.0 \times 10^{-5}$ with the increase in $H_{*}$. An order of magnitude lower $S_{f}$ and, consequently, $S_{e}$-values at the GS1 could also be attributed to the influence of the downstream bridges.

Friction losses dominate over the losses due to momentum transfer for lower $H_{*}$-values at both $G S\left(H_{*} \leq 0.20\right.$ at the GS1 and $H_{\star} \leq 0.25$ at the GS2). As it was already discussed, the reason for such a distribution between partial head losses might be explained by the operation of the downstream sluice gate, which controls the water profile in that part of the irrigation and drainage system. For lower $H_{*}$-values the whole reach is under the strong backwater effect with no significant momentum exchange between subsections of the compound channel. Thus, the $S_{f}$ dominates especially at the GS2. This can be explained by the fact that there are no additional obstacles downstream of the GS2 besides densely vegetated floodplains. Therefore, the piezometric slope between the sluice gate and the GS2 is greater than that between the GS2 and the GS1, which explains greater $S_{f}$ values at the GS2. The contribution of the friction and additional losses due to the momentum transfer gradually equate with the increase in $H_{\star}$ at both stations. Since the two forces act in the opposite direction, the total head loss $\left(S_{e}\right)$ reduces with the increase in $H_{*}$.

\section{CONCLUSIONS}

The paper aimed at assessing the applicability of the exchange discharge model in estimating a stagedischarge curve at a river gauging station. The study has shown that:

i. One should be aware of the existing boundary conditions to correctly encounter and understand different controls to the compound channel flow, both in constructing the stage-discharge curve and in its engineering applications; 
ii. When the gauging station is in the zone of influence of backwater (water surface profile of M1-type) the DCM under predicts the discharge at high floodplain depths, where the uncertainty in the prediction of high water flows is very high. Thus, the application of the EDM would provide higher level
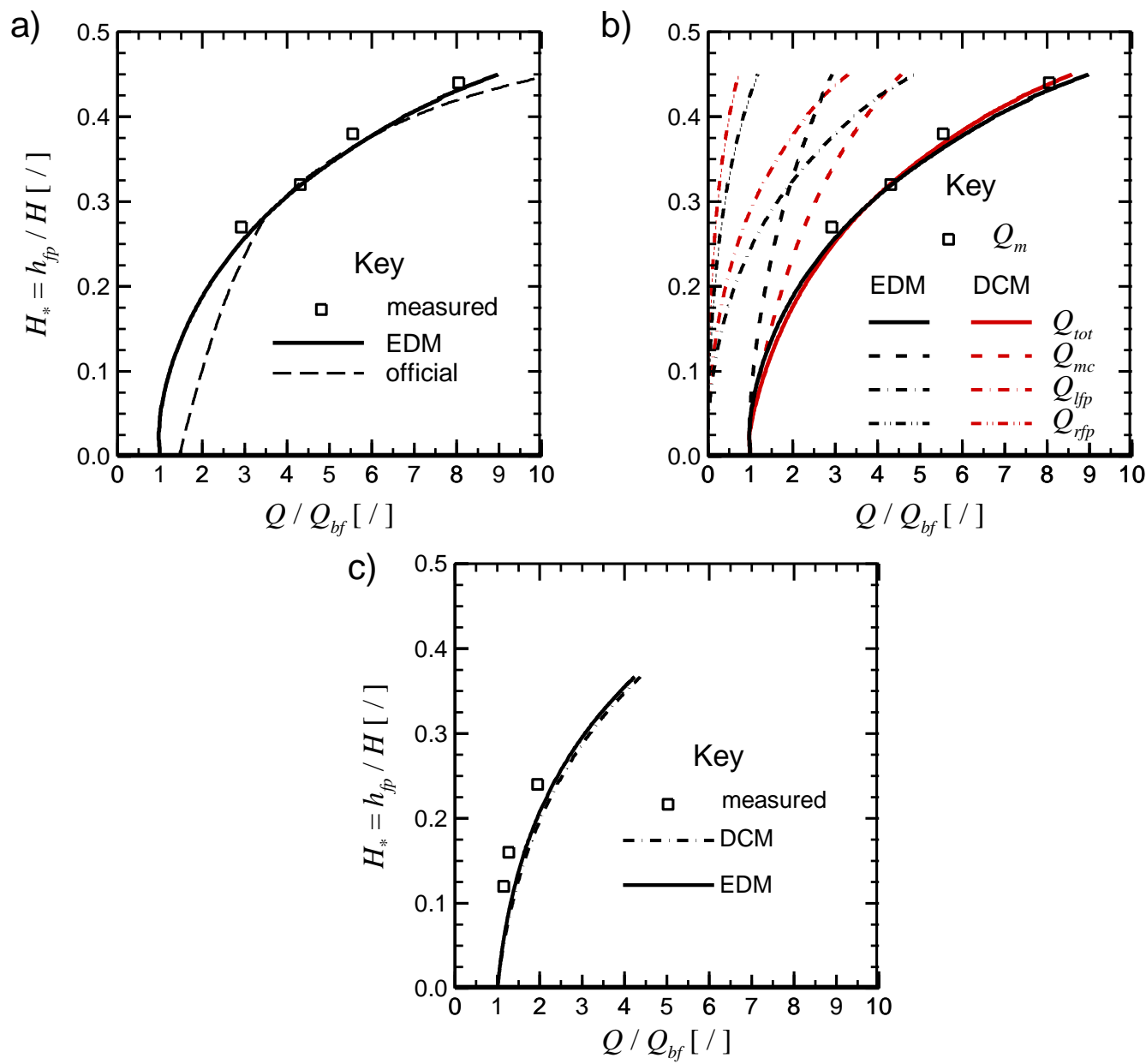

Figure 4. a) Verification of EDM for stage-discharge curve at GS1; b) division of the total overbank flow discharge $\left(Q_{t t t}\right)$ into the main channel $\left(Q_{m c}\right)$, left and right floodplain discharges $\left(Q_{l p}\right.$ and $\left.Q_{r f p}\right)$, respectively; and c) verification of EDM at GS2

a)

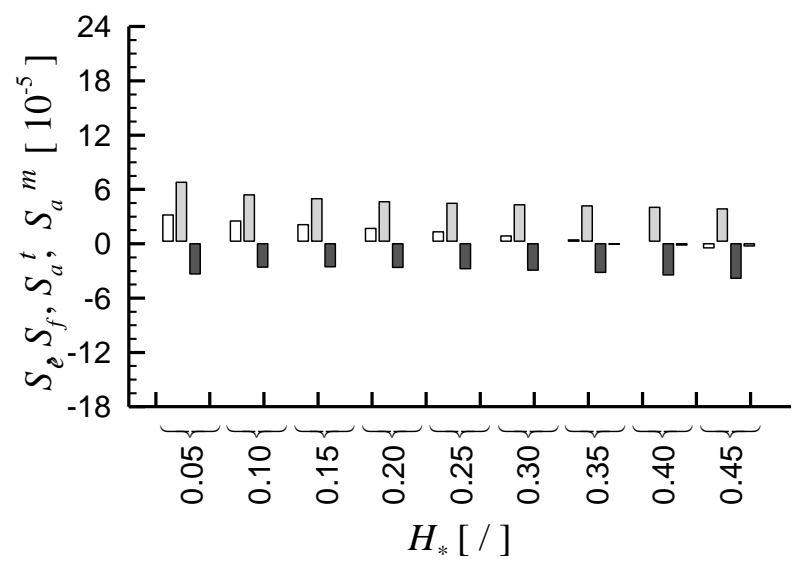

b)

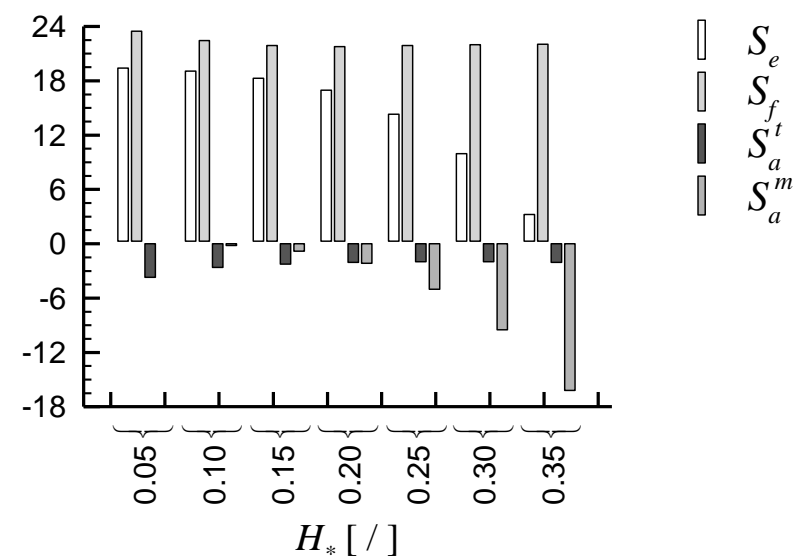

Figure 5. Total and partial head losses at: a) GS1 (1999) and b) GS2 (2013) for different floodplain submergence ratios $H_{*}$

of confidence in the planning and the design stages of flood control structural and non-structural measures. On the other hand, the application of the EDM in defining the stage-discharge curve at a 
gauging station on the stretch of the river where M2-type water surface profile exists, would result in lower flood discharge values and consequently in the cost-effective solutions;

iii. The EDM parameter values depend on the hydraulic conditions at a gauging station. When the gauging station is under the influence of backwater, the value of $\psi^{t}$ increases and the effect of the non-prismaticity of a compound channel is almost negligible. However, when the water surface profile at the gauging station is of M2-type, the value of $\psi^{t}$ decreases and the momentum flux due to mass transfer becomes dominant. Nonetheless, the lower $\psi^{t}$-value does not result in smaller additional loss due to turbulence diffusion, since the velocity difference between the main channel and the floodplain increases;

iv. Although the difference between the DCM and EDM rating curves for the entire compound channel cross-section is not significant (only 3-4\%), the EDM gives more realistic discharge distribution between the main channel and the floodplains. The mass transfer due to non-prismaticity of the channel reduces the main channel discharge and, consequently, increases those on the floodplains, which is consistent with the laboratory observations.

v. With the estimated increase in the floodplain discharge by $30-40 \%$ in comparison to that calculated by the traditional DCM, it is easier to recognize the necessity for reforestation of floodplains as a measure for alleviation of harmful high water effects. The effect of floodplain vegetation on the discharge distribution will be addressed in the forthcoming studies.

\section{ACKNOWLEDGEMENTS}

The research reported herein is funded by the Ministry of Education and Science of the Republic of Serbia (37010).

\section{REFERENCES}

Bousmar, D., and Zech, Y. (1999). Momentum transfer for practical flow computation in compound channels. Journal of Hydraulic Engineering, 125(7), 696-706.

Bousmar, D., Wilkin, N., Jacquemart, J.H. and Zech, Y. (2004). Overbank flow in symmetrically narrowing floodplains. Journal of Hydraulic Engineering, 130(4), 305- 312.

Bousmar, D., Proust, S. and Zech, Y. (2006). Experiments on the flow in a enlarging compound channel. River Flow 2006: Proc. Internat. Conf. on Fluvial Hydraulics, Lisbon, Portugal, Taylor and Francis, Leiden, Netherlands, 323- 332.

Das, B.S. and Khatua, K.K. (2018). Flow resistance in a compound channel with diverging and converging floodplains. Journal of Hydraulic Engineering, 144(8), 1-21.

Đorđević, D., Stojnić, I. and Rosić, N. (2017).Water profile computations in non-prismatic compound channels with simple cross-sectional geometry using exchange discharge model. (in Serbian) Vodoprivreda, 49(288-290), 349-361.

Đorđević, D., Ivković, M. and Stojnić, I. (2018). Application of the exchange discharge model for the estimation of the rating curve in the compound channel - a case study. (in Serbian) Proc. 18th Conf. of SAHR and $S A H$, Niš, Serbia, Faculty of Civil Engineering, University of Belgrade, 349-361.

Ikeda, S. and McEwan, I.K. (2009). Flow and sediment transport in compound channels. IAHR Monograph Series. CRC Press, Taylor \& Francis Group, $327 \mathrm{pp}$.

Knight, D.W. and Shiono, K. (1987).The SERC Flood Channel Facility. Water and Environment Journal, 1 (2), 198-204.

Proust, S., Riviere, N., Bousmar, D., Paquier, A. ,Zech, Y. and Morel, R. (2006). Flow in compound channel with abrupt floodplain contraction. Journal of Hydraulic Engineering, 132(9), 958-970.

Proust, S., Bousmar, D., Riviere, N., Paquier, A. and Zech, Y. (2009). Non-uniform flow in compound channel: A 1-D method for assessing water level and discharge distribution. Water Resources Research, 45, W12411.

Proust, S., Fernandes, J.N., Peltier, Y., Leal, J.B. Riviere, N. and Cardoso, A.H. (2013). Turbulent non-uniform flows in straight compound open channels. Journal of Hydraulic Research, 51:6, 656-667.

Stojnić, I., Muhić, F. and Đorđević, D. (2015). Study of the influence of channel geometry and hydraulic resistance on flow characteristics in compound channels with the exchange discharge model. (in Serbian) Vodoprivreda, 47(276-278), 261-268. 